\title{
TERRITORIALIZAÇÕES PRECÁRIAS NA CIDADE: UM ESTUDO DE CASO SOBRE AS CRACOLÂNDIAS
}

\author{
PRECARIOUS TERRITORIALIZATIONS IN THE CITY: THE CRACOLÂNDIAS \\ STUDY CASE
}

\author{
Felipe Rangel Tavares \\ Mestre em Geografia - PUC Rio. \\ tavares.geo@gmail.com
}

\section{Resumo}

O presente artigo é um desdobramento da pesquisa ${ }^{1}$ realizada no Programa de Pós Graduação em Geografia da PUC Rio ${ }^{2}$. A cidade do Rio de Janeiro passa por um processo de produção espacial banalizado. Uma expressão de tal banalização do espaço é percebida a partir das "cracolândias", como popularmente as cenas de crack são conhecidas. "Cracolândia" é uma representação que oculta e mascara as contradições do espaço, uma faceta da urbanização banalizada. Percebemos que distintas representações do espaço engendram práticas e usos na cidade que constituem uma vida cotidiana dirigida ao consumo, organizada e programada - basta observar os inúmeros aparatos de segurança e vigilância que surgem para combater o medo e a violência. Dois processos atuam reforçando a cracolândia como uma representação do espaço: a mercadificação e a militarização. As medidas e ações adotadas pela governança urbana apontam para um descolamento, fragmentação e redução dos fatores que compõem a questão: os usuários de drogas ora são vistos como casos de polícia, ora como casos de saúde pública. A crise que se expressa é de ordem social e isto está estritamente relacionado à dimensão espacial. Portanto, torna-se necessário investigar as contradições mascaradas por representações que bloqueiam o possível e impedem a plena realização do indivíduo na cidade.

Palavras-chave: cracolândias, representações do espaço, banalização, territorialização precária.

\footnotetext{
${ }^{1}$ Agradeço à CAPES pela concessão da bolsa durante todo o período de realização desta pesquisa.

${ }^{2}$ Orientada pelo Professor Dr. Alvaro Ferreira.
} 


\section{Introdução}

Diante do agravamento do consumo de crack no Brasil, o Governo Federal brasileiro adotou grandes medidas nos anos de 2010 e 2011, segundo o relatório publicado em setembro de 2013 na página eletrônica da Fundação Oswaldo Cruz (Fiocruz). Conforme este documento, tal gravidade pode ser observada do ponto de vista social e igualmente de saúde. A presidência da República publicou o Decreto $\mathrm{n}^{\circ} 7.719$, que institui o "Plano Integrado de Enfrentamento ao Crack e outras Drogas", em 2010, e o "Programa Crack é possível vencer", em 2011, com medidas de integração de ações em três eixos - prevenção, cuidado e autoridade (Fiocruz, 2013). Em 2013, foi realizado no Brasil, o que se chamou, de "o maior estudo" sobre usuários de crack e/ou similares nas Capitais do país, que por sua escala de abrangência representa a pesquisa de maior ordem de magnitude em relação aos demais estudos anteriores. Seus principais objetivos foram delinear o perfil da população usuária de crack e/ou similares (formas similares de cocaína fumada - pasta base, merla e "oxi"); além de estimar o número desses usuários.

Conforme o estudo realizado, que entrevistou aproximadamente 25.000 pessoas residentes nas capitais do país, o total de usuários de crack e drogas similares no Brasil são de 370 mil (nas capitais do país e no Distrito Federal), sendo que 50 mil usuários são crianças e adolescentes. $O$ estudo aponta que os espaços públicos de interação e circulação de pessoas são os locais de consumo da droga. Apesar da pesquisa definir uma localização, o relatório divulga a dificuldade de mapeamento pela mobilidade das "cenas de crack" (como são denominados os locais onde se realizam a venda e o consumo da droga).

Dentre as análises publicadas neste relatório de estudo, destacamos algumas informações fundamentais para entendermos esse fenômeno que se disseminou pelas grandes capitais e tem sido noticiado pela grande mídia. Primeiramente, as estimativas de proporção de usuários de crack e/ou similares não são mais elevadas nas capitais da região Sudeste, contrariando a percepção do senso comum. Conforme a pesquisa, o consumo nestas regiões 
ocorre em locais públicos onde a visibilidade é maior "devido à magnitude das suas metrópoles e o tamanho expressivo das grandes cenas de uso conhecidas como "cracolândias'” (Fiocruz, 2013). Em números absolutos (considerando o tamanho populacional), o número de usuários de crack nas capitais do Sudeste é de aproximadamente 115 mil. Os dados sobre moradia apontam que $40 \%$ dos usuários no Brasil se encontram em situação de rua, embora, conforme o relatório, não se possa afirmar, de modo simplista, que eles são uma população de rua, pois se considera que parte expressiva de seu tempo é nas ruas. Nas capitais, $47,7 \%$ estão em situação de rua. O sexo masculino predomina como usuário (78,7\%); em relação à faixa-etária, prevalece o uso entre adultos e jovens com idade média de 30 anos; e, em relação à raça/cor, há o predomínio de "não-brancos", que de acordo com o IBGE (Instituo Brasileiro de Geografia e Estatística) correspondem a 52\% da população brasileira, representados por pretos e pardos em contextos de vulnerabilidade social.

Atualmente, as cenas de crack provocam intensos debates e polêmicas no que diz respeito ao modo de solucionar a questão, e, além disso, é um quadro explícito da banalização da cidade, cujo modelo de desenvolvimento e estratégias estão direcionados aos investimentos em infraestrutura para os megaeventos, empresas estrangeiras e classe média. Essa orientação é o que tem provocado um aumento do contingente policial e das medidas de controle e vigilância na cidade, pois é preciso que o Estado proteja a propriedade privada para criar um clima favorável de negócios e não perder seu relacionamento com os investidores, nem comprometer a vitrine internacional que é a cidade do Rio de Janeiro - deve haver segurança para o consumo. A contradição reside no fato de que, dois processos têm sido mobilizados por representações distintas: a mercadificação e a militarização do espaço. Embora ambos estejam atrelados, um se utiliza da representação que busca promover imagem da cidade como maravilha, uma fantasia exuberante, magnífico de se viver e consumir, enquanto outro se serve das representações opostas, as que estimulam o medo, o pavor e a insegurança. Neste sentido, nosso objetivo é investigar a dimensão espacial das cenas de crack na cidade, levando em 
conta os processos e representações que as condicionam, sendo estas o resultado do agravamento da crise social provocada pela reestruturação produtiva do capital na década de 1980.

\section{Cracolândia: uma representação do espaço}

Quando tratamos sobre as "Cracolândias", estamos nos referindo a uma representação construída socialmente para definir e caracterizar um determinado espaço, tal como controlá-lo e dominá-lo. As cenas de crack, ou, como são vulgarmente chamadas, as Cracolândias surgem em São Paulo, na década de 1990, no chamado "Quadrilátero do Crack" (também uma representação), na área central paulistana: Praça da Sé, Rua Guaianazes e vários outros logradouros do Central Business District ou de seu entorno obsolescente (Souza, 2005). Embora "Cracolândia" seja uma representação, ela adquire um caráter material: se realiza concretamente no espaço, principalmente quando os veículos de comunicação se apropriam deste caráter simbólico para difundir suas opiniões acerca da violência e insegurança na cidade. As representações se assentam sobre uma superfície material e passam a identifica-las, gerando imaginários e juízos de valor.

A partir de algumas reportagens extraídas do site do jornal Estadão, observamos que as notícias atribuem a denominação "cracolândia" às áreas violentas, problemáticas e inseguras, local de atividades como tráfico, prostituição, também, como lugares sujos e perigosos. Diante dos estigmas sociais já atribuídos a estes lugares, se assoma o termo "cracolândia". O uso da expressão nas manchetes também apresenta a força que a representação adquire, pois, mesmo sendo de caráter simbólico, legitima ações concretas, como as publicadas abaixo:

“Megablitz na Cracolândia tem poucos resultados" (20/05/2002).

"Prefeitura promete começar no mês que vem a demolir Cracolândia" (09/03/2007).

“Cracolândia resiste à revitalização” (07/06/2008).

"Cracolândia abastece todas as classes" (21/07/2009).

"Mesmo ocupada, Cracolândia resiste" (23/07/2009). 
De acordo com Harvey (2006), as representações são uma parte integrante de nosso modo de viver no mundo, pois sempre procuramos representar a maneira que este espaço é, seja pela cientificidade de filósofos, seja emocionalmente, afetivamente, através das artes, poesias, desenhos e imagens. Segundo Harvey (2006), "a experiência física e material da ordem espacial e temporal é mediada, em um certo grau, pela maneira com que espaço e tempo são representadas", afetando "tanto nossas experiências diretas quanto nossa interpretação e compreensão". As cracolândias se inserem neste âmbito - consistem em representações do espaço, constituídas "de cima para baixo" - pois são os meios de comunicação que se encarregam de reforçar sua presença. De acordo com Lefebvre (1991), as representações do espaço (espaço concebido) estão ligadas às relações de produção, à ordem que elas impõem, aos signos, aos códigos dos cientistas, arquitetos e urbanistas, planejadores, identificando o percebido e o vivido ao concebido.

A obra de Lefebvre La présence et l'absence (A presença e a ausência, 1980) é crucial para compreender o papel das representações no espaço, pois o autor reconhece que as representações não se distinguem em verdadeiras e falsas, nem se reduzem à linguagem nem aos seus suportes sociais. Lefebvre afirma que as representações circulam em torno de fixos (instituições, símbolos e arquétipos), interpretam a vivência e a prática; intervém nelas sem conhecêlas nem dominá-las; formam parte delas, e, somente pela análise podemos distingui-las (Lefebvre, p.28, 1983). De acordo com o filósofo, as representações não são nem falsas e verdadeiras, mas ao mesmo tempo, falsas e verdadeiras: "as representações são falsas no que apontam e dizem, mas verdadeiras em relação ao que as suporta" (p.52, 1983). Quando o representado é substituído pelo representante, por meio da representação, esta se consolida, e o mundo das representações se realiza socialmente, se converte no real. Lefebvre lança uma série de questões iluminadoras:

Quem engendra ou produz as representações? De onde emergem? Quem as percebe e as recebe? Que sujeito? E, que faz com elas? É o sujeito individual e/ou social que produz as representações? De acordo com quais processos? Ou bem, pelo contrário, se constitui a 
partir de representações emitidas por outros sujeitos? A menos que não tenham nem sujeito nem objeto definíveis (Lefebvre, p.24, 1983). ${ }^{3}$

Quem produz as representações? Os "cracudos"(como vulgarmente são chamados)? Para os usuários de crack, estes ambientes são lugares de sociabilidade; eles não se enxergam inseridos em cracolândias. $O$ antropólogo norte-americano Philippe Bourgois declarou, numa entrevista publicada pelo jornal Estadão (10/12/2010), que a Cracolândia "se trata da mais sociável e amigável cena de crack que já visitou" (...) "não se vê em outros lugares esse nível de relaxamento e sociabilidade, pessoas fazendo música, com prazer e alegria, enquanto fumam crack". Buscando responder a este questionamento, identificamos na cidade do Rio de Janeiro uma conformidade com um modelo baseado numa lógica empresarial que pretende gerar um clima favorável aos negócios, onde a publicidade e a propaganda são aliadas fundamentais, atuando em conjunto na constituição de um produto, uma mercadoria. Este modelo é engendrado por uma governança urbana, que de acordo com Harvey (2005) é um conjunto complexo de forças mobilizado por diversos agentes sociais: algo muito mais que "governo" urbano, pois diz respeito à coalizão de forças, onde está, segundo o autor, o poder real de organização da vida urbana. Deste modo, concordamos com Peet (2007, p.32) quando aborda a questão do desenvolvimento apresentando a noção de "complexos institucionais hegemônicos", formados por atores econômicos, ideológicos, midiáticos e políticos, "para produzir ideias e políticas com suficiente profundidade teórica e apoio financeiro para dominar o pensamento sobre vastos campos de poder", isto é, sobre o espaço. Arquitetos, urbanistas, técnicos, empresários, mídia e políticos, todos compartilham de um mesmo discurso, único e hegemônico, em detrimento dos múltiplos territórios e das múltiplas territorialidades que compõem o espaço urbano.

\footnotetext{
${ }^{3}$ Quién engendra o produce las representaciones? Dónde emergen? Quién las percibe y las recibe? Qué sujeto? Y qué hace com ellas?Es el sujeto individual y/o social el que produce las representaciones? Según qué proceso? $\mathrm{O}$ bien por el contrario se constituye a partir de representaciones emitidas por otros sujetos? A menos que no tengan ni sujeto ni objeto definibles? (Lefebvre, p.24, 1983).
} 
O processo de produção do espaço da cidade do Rio de Janeiro, atualmente, pode ser observado a partir de obras de "revitalização urbana", cuja finalidade é atrair visibilidade internacional e investimentos privados para inserir a cidade num circuito de competição e consumo global, o que inviabiliza a permanência da população de renda mais baixa e impele à expulsão dos mais pobres. Simultaneamente à mercadificação do espaço, via revitalizações e requalificações urbanas, a governança urbana, por meio de políticas públicas e outras ações, busca, através de programas do governo federal, erradicar a pobreza e combater a miséria. Porém, a forma que temos assistido a tudo isso no Rio de Janeiro é um tanto contraditória. Instalação de Unidades de Polícia Pacificadora em favelas, operações policiais em conjunto com as forças armadas (os equipamentos bélicos assustam!), apelo cada vez maior aos sistemas de vigilância e segurança, sem esquecer a "Cidade da Polícia", um complexo que é estabelecido numa área de $41.000 \mathrm{~m}^{2}$ num terreno de uma antiga fábrica da Souza Cruz. Pobreza associada à criminalidade e violência. Em suma, o processo de fragmentação e segregação do espaço é ampliado pela mercadificação e militarização, que "encarcera" as classes em seus respectivos espaços, ricos em seus "guetos de opulência", condomínios de luxo e shopping centers; e os pobres nas favelas, nas linhas ferroviárias, nas ruas, debaixo de viadutos, em territorializações precárias.

Neste sentido, quando a droga chega ao Rio de Janeiro (e acreditamos que da mesma forma, em outras cidades), as representações do espaço dos usuários de crack já estão bem consolidadas e se difundem pelos veículos de comunicação (jornais, telejornais, rádio e internet) e, principalmente, no cotidiano da cidade. Ocorre que, pelas diferenças entre as morfologias urbanas de São Paulo e Rio de Janeiro, os usuários não se concentram em grande número na área central da cidade, mas, nas proximidades das favelas que comercializam a droga (no interior dos trechos ferroviários, entre tapumes de obras, em espaços públicos degradados). Apesar disso, observamos que os espaços públicos abandonados ou degradados da cidade logo adquirem o valor simbólico de Cracolândias, ainda que não haja o consumo da droga no local, ou seja, o uso da representação se amplia e passa a denotar ambientes 
sujos, deteriorados, insalubres, com a presença de moradores de rua. O que desejamos ressaltar é que a Cracolândia consiste numa representação do espaço que não descarta um aspecto físico ou material, isto é, se realiza a partir de fixos e também possui uma forte carga simbólica. Podemos assim considerar que a cracolândia é uma representação falsa e verdadeira - falsa em relação ao que aponta, verdadeira em relação ao que a suporta. Se admitirmos tal representação sem o devido exame crítico, sustentamos as contradições que são escamoteadas pelos atores hegemônicos que dominam o espaço. Nesse sentido, é preciso atentar para o que as suporta, e, para tal, é indispensável considerar as cracolândias em seu aspecto concreto, material, como uma territorialização precária.

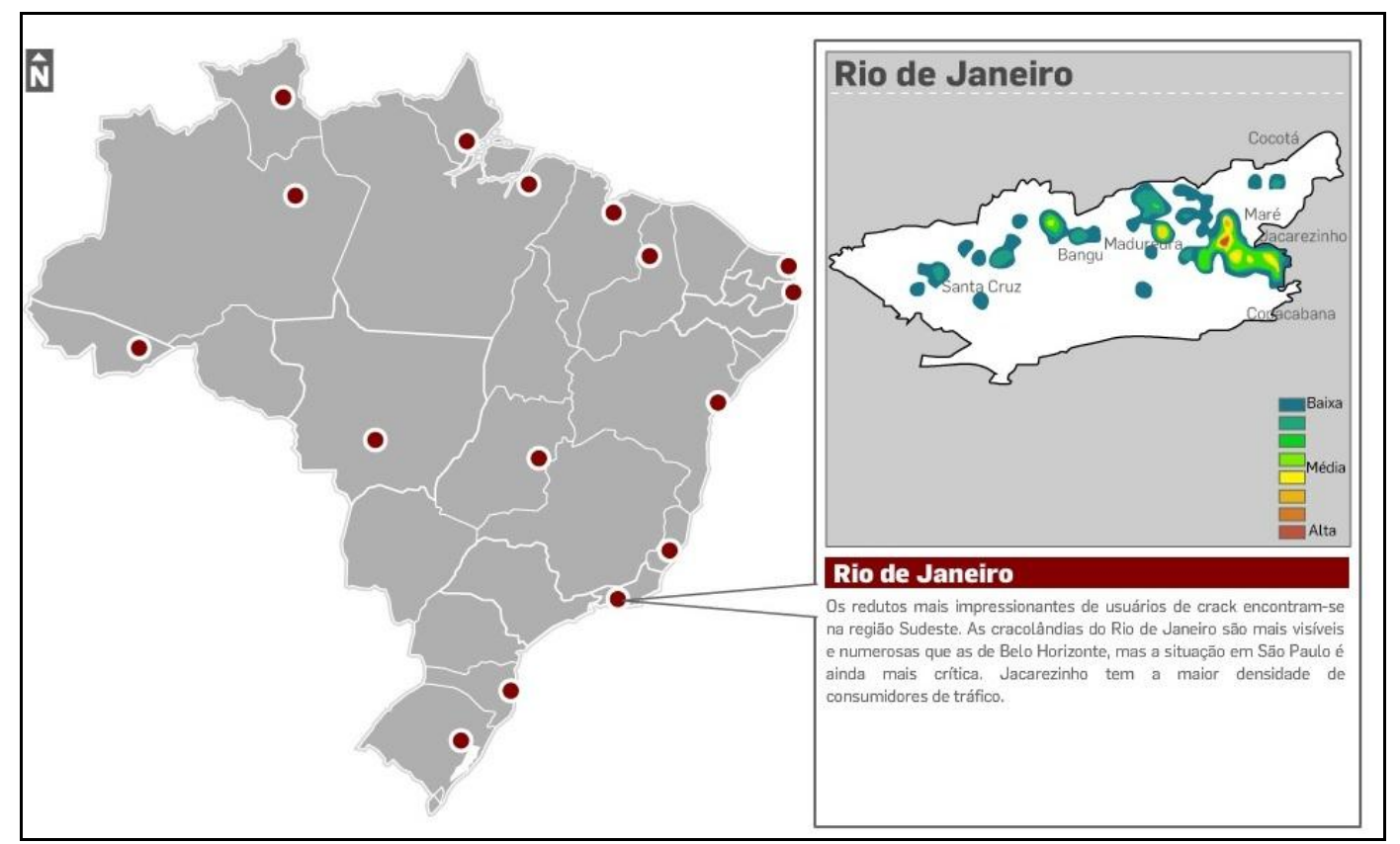

Figura 1 - Cenário do crack no Brasil. Extraído do site do Jornal Estadão, acesso 10 de fevereiro de 2014. Mapeamento realizado pela Secretaria Nacional Antidrogas em Parceria com a Fundação Oswaldo Cruz. O texto informa o seguinte: os redutos mais impressionantes de usuários de crack encontram-se na região Sudeste. As cracolândias do Rio de Janeiro são mais visíveis e numerosas que as de Belo Horizonte, mas a situação em São Paulo é ainda mais crítica.

Distintas representações da cidade entram em conflito: A cidade do medo e da insegurança, da "guerra civil" é a cidade da paz, segura e pronta para receber de abraços abertos seus visitantes. A produção hegemônica de um território homogeneizante e "homogeneizador", fragmentado e hierárquico é possibilitada pela existência de distintas representações que são recurso para 
legitimar medidas e ações cujo propósito é garantir a gestão do capital, sua reprodução, através do espaço inteiro. Quando se faz necessário, estas representações servem de instrumento para justificar então processos de remoção da população pobre, incursões policias nas favelas, além das revitalizações e transformações urbanas na cidade. A cidade subsiste porque comporta esses símbolos e signos que causam distúrbio em quem a vive, moldando o comportamento, os usos, e o pensamento, o espaço concebido. A produção de uma cidade que reflete uma sociedade do controle nos mostra 0 quanto a violência contra a liberdade, ou autonomia, orientam e definem os usos, as concepções a vivência no/do espaço. Declara uma cidade sem saídas, onde não existem alternativas - um espaço cartesiano e absoluto, imutável, fechado, onde todas as interações já ocorreram, sem possibilidades de transformação. Esta é a condição para que a reprodução seja garantida. Entretanto, como Lefebvre (2008) nos mostrou, um espaço fechado, como uma prisão, é o espaço da contestação, do protesto, portanto, das possibilidades. Considerar o espaço aberto e sempre em construção é abrir novas perspectivas políticas para mudança, é cavar um túnel com uma colher para abandonar a prisão

De acordo com Lufti, Sochaczewski e Jahnel (1996), que afirmam baseadas em Lefebvre, somente "pela teoria pode-se escapar das representações enganosas que fascinam e trabalhar com aquelas que apontam para o novo, que contem o possível" (p.90, 1996). Para Lefebvre, a representação é produto de um determinado processo social, que, substituindo coisas, produtos e obras, torna-se socialmente concreta, referida à problemática da dominação e da exploração. Porém, nelas está o poder do anúncio do porvir, como dimensão do vivido, está os sonhos e as utopias, um caminho para o possível. Para Lefebvre, a teoria das representações permite mostrar como a consciência e o pensamento, sem omitir o real, se orientam até o possível, não sem riscos, e constrói o objeto virtual, bordejando constantemente o impossível. 


\section{Cracolândias como territorializações precárias na cidade}

No sentido de observar a cracolândia para além das representações que ocultam as contradições e atentar para seu aspecto concreto/material (e aquilo que a suporta), torna-se importante considerar os grupos sociais incluídos precariamente, compreendendo como Ferreira (2011), que eles atuam na produção do espaço e admitindo que a metrópole contem "lugares da exclusão", como as periferias e favelas. Entretanto, trataremos daqueles cuja presença é visível nas metrópoles e são considerados como sendo a expressão máxima da "exclusão social", os moradores de rua.

De acordo com Lago (2000), o aumento da concentração de renda no Brasil nas décadas de 1970 e 1980 elevou o grau de desigualdade social na região metropolitana do Rio de Janeiro em relação às demais regiões, o que representou, em termos absolutos, que o número de miseráveis (aqueles cujo rendimento familiar era inferior a um salário) era 2,7 vezes maior do que o referente aos que recebiam mais de vinte salários mensais.

Em 1980, residiam na metrópole 2,4 milhões de pessoas com renda
familiar abaixo de dois salários; em 1991, esse número pulou para 3,6
milhões (cerca de $37 \%$ da população metropolitana, que equivalem a
pouco mais de 1 milhão de famílias). Não se trata aqui da alteração
nas condições de reprodução da população pobre, e sim do aumento
relativo e absoluto dessa população, numa possível mobilidade social
descendente: setores médios empobrecidos, residentes em domicílio
alugado, vão engrossar as fileiras dos que não tem alternativa de
acesso à casa própria (Lago, p.160, 2000).

Este quadro de exclusão nos leva à discussão do termo, que segundo Lago (2000), está relacionado a uma vertente de análise sobre os efeitos socioespaciais da reestruturação econômica, que centrou-se na emergência da chamada nova pobreza urbana, traduzida nos Estados Unidos pela underclass e na Europa pelos excluídos. Segundo a professora, a noção de exclusão social se refere a uma nova divisão do trabalho, não mais marcada pela inserção diferenciada dos trabalhadores e sim pelos inseridos e pelos não inseridos no sistema produtivo hegemônico. É neste ponto que o conceito torna-se "inconceitual" e insuficiente como afirmou Martins (1997), pois empobrece a perspectiva de interpretação dos problemas relacionados ao tema. No modo produção capitalista não existem inseridos e não inseridos, 
todos estão incluídos, ainda que de forma precária. De acordo com Martins (1997), a exclusão, de fato, não existe sociologicamente; trata-se, na sociedade moderna, apenas de um momento da dinâmica de um processo mais amplo que nasce com a sociedade capitalista, cuja lógica própria é "desenraizar tudo e a todos excluir porque tudo deve ser lançado no mercado; para que tudo e todos sejam submetidos às leis do mercado" (p.30).

O capitalismo na verdade tudo desenraiza e brutaliza a todos, exclui todos. Na sociedade capitalista essa é uma regra estruturante: todos nós, em vários momentos de nossa vida, e de diferentes modos, dolorosos ou não, fomos desenraizados e excluídos. É próprio dessa lógica de exclusão a inclusão. A sociedade capitalista desenraiza, exclui para incluir, incluir de outro modo, segundo suas próprias regras, segundo sua própria lógica (Martins, p.32, 1997).

O debate é ampliado quando Fontes (1997) retoma o processo de expropriação, uma característica contraditória na sociedade capitalista observada por Marx. De acordo com a autora, tal lógica tendia a eliminar outras formas de produção social, incorporando-as logo em seguida. A formação de uma população livre e despossuída dos meios de produção de sua própria existência, detentora apenas de sua força de trabalho é o que caracteriza o processo de expropriação.

\footnotetext{
O processo de mercantilização da força de trabalho corresponde de fato a uma exclusão das condições anteriores de existência. (...) Porém, corresponde igualmente a uma inclusão, uma vez que essa mão-de-obra deveria estar apta para entrar no mercado de trabalho. (...) Expropriados da capacidade autônoma de sobrevivência e de parte do valor produzido por seu trabalho, mas incluídos em um processo mercantil e industrial que produzirá, ainda segundo Marx, as formas de pensamento para assegurar sua continuidade (Fontes, p.37, 1997).
}

Deste modo, Fontes (1997) designa o processo como uma inclusão forçada, que assegura a própria sobrevivência do sistema, ao submeter e disciplinar a força de trabalho necessário à sua existência. Isso se dá por meio da produção do espaço, de normas, decretos, leis e representações, que como observamos em Lefebvre (1986) constitui a base sobre a qual a sociedade está fundada. De acordo com Fontes (1997) a generalização da mercantilização da sociedade, componente essencial da expansão capitalista, reduzia (ou simplesmente eliminava) a possibilidade de sobrevivência individual fora do 
mercado, isto é, ninguém pode ser excluído do mercado. Portanto, se o espaço é concebido como uma mercadoria e o processo de mercadificação tem reforçado essa tendência, podemos entender que tanto a produção de formasconteúdo está submetida a esta lógica, quanto a nossa constituição como seres humanos, afinal, o espaço atua em na conformação de nossos comportamentos, sentimentos e pensamentos. A gravidade do problema, segundo Martins (1997) é que o período da passagem do momento da exclusão para o momento da inclusão está se transformando num modo de vida, está se tornando mais do que um período transitório. Podemos fazer um paralelo com o alerta para o risco da constituição de "populações desnecessárias", inclusive para a regulação capitalista (Fontes, 1997). O processo é tão perverso, que, como assinalou Martins (1997), a reinclusão se dá no plano econômico, mas não se dá no plano social, a reintegração não se dá sem deformações no plano moral, há uma desintegração social e moral. Este processo cria uma sociedade paralela que é includente do ponto de vista econômico e excludente do ponto de vista social, moral e até político (Martins, p.34, 1997).

\begin{abstract}
A nossa sociedade está se transformando numa sociedade dupla, duas "humanidades" na mesma sociedade. De um lado, uma humanidade constituída de integrados (ricos e pobres). Todos, inseridos de algum modo, decente ou não, no circuito reprodutivo das atividades econômicas: todos têm o que vender e o que comprar. (...) Mas está crescendo brutalmente no Brasil uma outra sociedade que é uma sub-humanidade: incorporada através do trabalho precário, no trambique, no pequeno comércio, no setor de serviços mal pagos ou, até mesmo, excusos, etc (Martins, p.36, 1997).
\end{abstract}

A iluminação que Martins (1997) traz acerca do que não seria mais o "mundo dos pobres", mas a constituição de uma sub-humanidade inserida a partir condições precárias, nos leva a considerar a questão da pobreza urbana e o "circuito inferior", desenvolvida por Milton Santos (2004). De acordo com o geógrafo, o atual modelo de crescimento econômico é responsável por uma distribuição de rendas cada vez mais injusta e impede a expansão do emprego, tendo como umas das principais consequências dessa situação, a existência do circuito inferior da economia urbana. O resultado é que, à medida que o país se industrializa, a urbanização torna-se cada vez mais terciária (Santos, p.193, 
2004). São exemplos dessa situação o aumento da oferta de empregos de "pedreiro", acompanhados da promoção de cursos profissionalizantes e oportunidades na construção civil (devido a necessidade de mão-de-obra barata para atuar nas obras para os megaeventos que acontecerão na cidade, Copa do Mundo - 2014, e Jogos Olímpicos, 2016).

Na realidade, a pobreza agrava-se por toda a parte, tanto nos países subdesenvolvidos que ingressaram recentemente "no caminho do progresso material", como naqueles que começaram antes seu processo de integração nas ideias de progresso. A razão disso é que a modernização tecnológica engendra disparidades sociais e econômicas crescentes. A alocação de uma importante parte dos recursos nacionais é feita em nome do progresso em benefício daqueles que já são ricos e ao preço de uma injustiça crescente (Santos, p.193, 2004).

Milton Santos destaca que a carga mais pesada da modernização é paga pelos pobres, os que estão bem abaixo na escala dos salários, e os que estão sem emprego, o que os leva a ter um orçamento deficitário, no qual o dinheiro líquido é algo raro, e, ao invés de gastá-lo no aluguel de uma casa ou em outros consumos essenciais, as pessoas são induzidas a preferir outros tipos de consumo, que são pagos à vista ou a crédito.

Essa situação é responsável pela criação ou pela manutenção do que
chamamos de circuito inferior da economia urbana dos países
subdesenvolvidos. Os pobres não tem acesso aos produtos
modernos e os mais pobres dentre eles só podem proporcionar-se
consumos correntes por intermédio de um sistema de distribuição
particular frequentemente completado por um aparelho de produção
igualmente específico e que é uma resposta às condições de pobreza
da grande massa da população. (...) Portanto, sem se levar em
consideração esse circuito inferior, a compreensão da cidade é
incompleta (Santos, p.196, 2004).

Discutindo a segregação de modo espacializado, isto é, observando a fragmentação do espaço, Souza (2005) também fornece um quadro do contexto social nas décadas de 1980-90, citando o desemprego no setor industrial, a precarização das condições de trabalho, com o aumento da informalidade; e no limite, o estímulo ao incremento de estratégias de sobrevivência ilegais, especialmente as relacionadas ao subsistema de varejo do tráfico de tóxicos. Ele chama atenção para o que tem se constituído nas metrópoles como uma parcela da população que seria irrelevante. Retomando a definição de lumpemproletariado, cunhada por Marx para caracterizar os 
mais pobres entre os pobres (criminosos, prostitutas, mendigos, entre outros), Souza (p.192, 2005) afirma que "as metrópoles são cada vez mais um lócus da pobreza e da miséria, assim como por tabela, da insegurança e da violência", pois esta camada social cresce em importância numérica e política no Brasil (p.189), porém, ele não enxerga nestes a possibilidade de serem agentes radicalmente transformadores, para o autor:

O modus vivendi do lumpemproletariado é parasitário, enquanto pedinte que vende sua própria degradação, ou ironicamente simbiótico com o capitalismo periférico, enquanto agente econômico operando no circuito inferior da economia urbana; ou ainda, parasitário-simbiótico, enquanto criminalidade que vive do vício de seus consumidores e se serve da corrupção e da violência como instrumentos de trabalho (Souza, p.190, 2005).

Outra importante contribuição, que converge neste sentido de considerar os grupos sociais incluídos precariamente nas metrópoles e seu modo de vida, tal como a forma com que esses grupos vulneráveis se espacializam, é a do professor Rogério Haesbaert (2004), que traz a noção de exclusão como desterritorialização, observada na sua múltipla dimensão, econômico-política e simbólico-cultural. Conforme o professor:

Desterritorialização, se é possível utilizar a concepção de uma forma
coerente, nunca "total" ou desvinculada dos processos de (re)
territorialização, deve ser aplicada a fenômenos de efetiva
instabilidade ou fragilização territorial, principalmente entre grupos
socialmente mais excluídos e/ou profundamente segregados e, como
tal, de fato impossibilidade de construir e exercer efetivo controle
sobre seus territórios, seja no sentido de dominação político-
econômica, seja no sentido de apropriação simbólico-
cultural.(Haesbaert, p.312, 2004)

Para isso ele propõe a noção de "aglomerados humanos de exclusão", com a finalidade de abarcar situações de difícil mapeamento, que escapam da abordagem de território (ou territorialização) no sentido de uma zona razoavelmente bem delimitada, e que fogem do sentido de uma rede cujos fluxos são definidos e controlados pelos seus próprios produtores e usuários.

Escolhemos a expressão "aglomerados de exclusão" para traduzir a dimensão geográfica ou espacial dos processos mais extremos de exclusão social porque ela parece expressar bem a condição de "desterritorialização" - ou de "territorialização precária" - a que estamos nos referindo, a começar pelos próprios significados que carrega no senso comum (Haesbaert, p.313, 2004). 
Embora seja uma aproximação importante no que diz respeito ao reconhecimento de tais grupos cuja apreensão investigativa seja mais complexa de realizar por conta de sua instabilidade espacial, isto é, a sua nãofixação permanente, como é o caso das Cracolândias e dos moradores de rua, que estão em constante movimento, trouxemos tal contribuição, em primeiro lugar, para dar ênfase à presença desses grupos sub-humanizados,muitas vezes ignorados ou "invisibilizados", ressaltando a importância de estudá-los sem reduzir a análise ao nível sociológico ou antropológico, mas considerando a dimensão espacial de sua existência, uma vez que seus corpos ocupam espaço, nas ruas, em calçadas, debaixo de viadutos, em prédios abandonados; e em segundo lugar, para demonstrar a dificuldade de lidar com suas espacializações extremamente móveis, instáveis e imprevisíveis (em sua maioria, como processos temporários), enfatizando assim, conforme Haesbaert (2004), a desterritorialização,

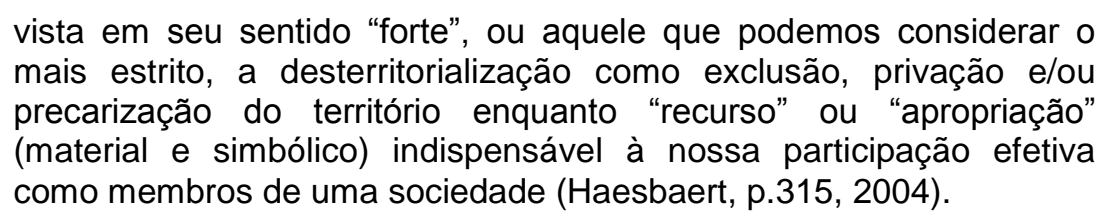

Portanto, não utilizaremos o termo "aglomerados de exclusão" para denominar a territorialização desses grupos incluídos precariamente no plano econômico, mas destituídos social, moral e politicamente. Entretanto, consideraremos como Haesbaert (2004) apontou, que, do mesmo modo que Martins (1997) afirma que não há exclusão social, também não há a completa exclusão e/ou privação territorial, isto é, a desterritorialização num sentido absoluto: o próprio movimento imprevisível e instável desses grupos apresenta sua (re)territorialização precária. Ele chama atenção para o fato de que cada vez mais são criadas áreas completamente vedadas à habitação/circulação humana, ou seja, quando o espaço é concebido como uma mercadoria, mais ele se presta à dominação, logo, menos ele se presta ao uso, à apropriação. A militarização do espaço reforça essa tendência, pois a coerção e a repressão estatal, por meio da polícia e seus aparatos de controle e vigilância, dissolve a vivência democrática e participativa, o direito à cidade e a liberdade. 


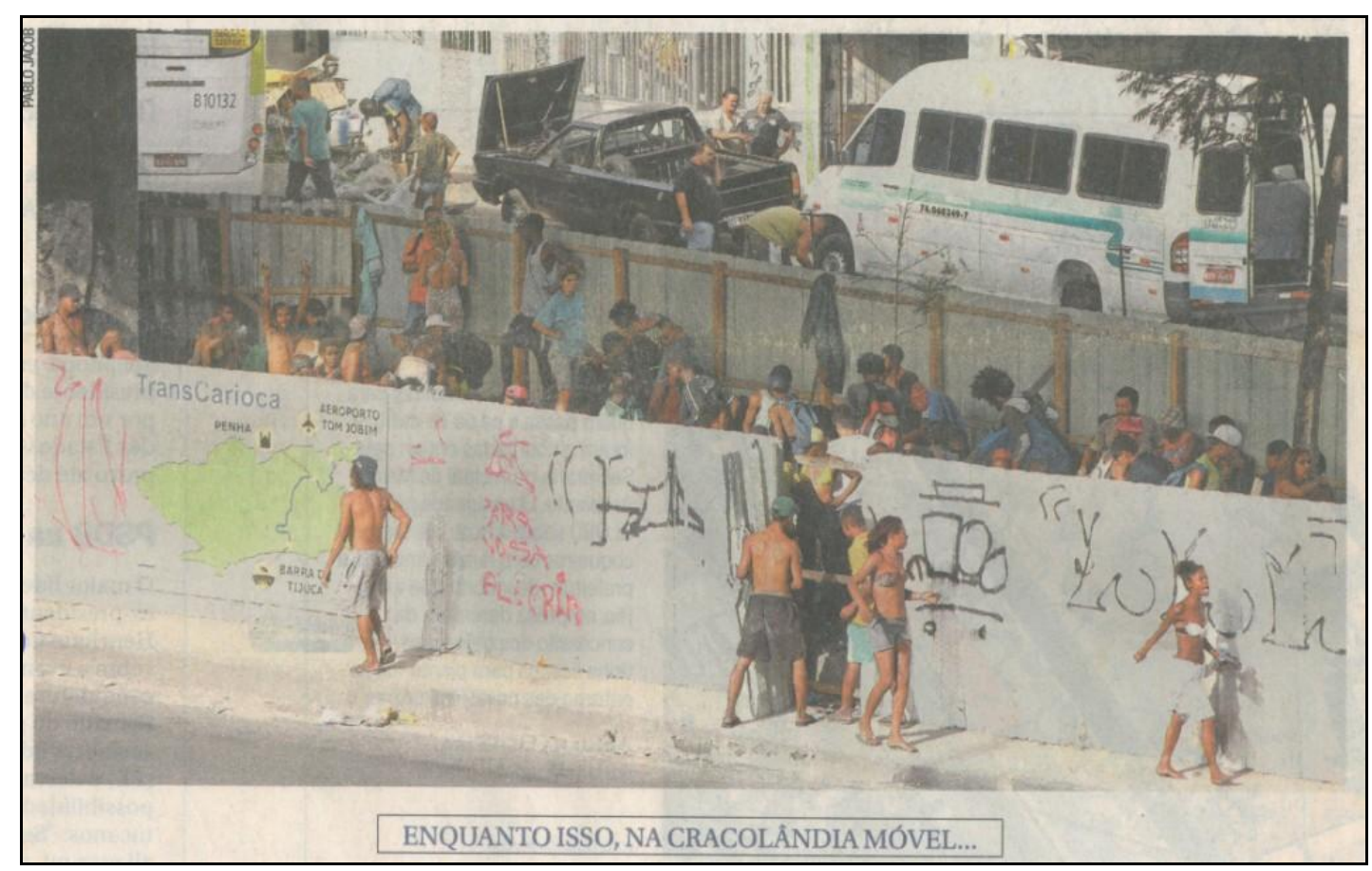

Figura 2 - "Cracolândia móvel". Jornal O Globo, 17 de outubro de 2012. Usuários de crack ocupando os tapumes da TransCarioca.

Embora visíveis ou escondidas, as cenas do crack têm aspectos em comum que tornam explícitas as formas de precarização e degradação vivida não apenas por adultos, mas em grande parte por crianças e adolescentes, expostos à situação de vulnerabilidade, morando nas ruas, incluídos precariamente num cotidiano perverso e opressivo, que é produto de processos mais amplos que as medidas pontuais, simplórias e emergenciais tomadas por parte da Prefeitura municipal do Rio de Janeiro. A partir do perfil dos usuários de crack, podemos perceber a posição que estes indivíduos "subhumanizados", nas palavras de Martins (1997), ocupam na sociedade: a classificação para pesquisa estatística é uma representação de tal miséria populações invisíveis ou ocultas.

\section{Considerações finais}

A banalização do espaço, pelas vias da expropriação do trabalhador e da reificação das relações sociais, rouba do ser humano sua essência criativa, transformando-o numa mercadoria, num objeto; mascara as relações sociais 
entre os homens e as realidades espirituais e psíquicas, reorientando o sentido de existência ao mercado e ao consumo. A cracolândia é uma representação que expressa a banalização do espaço, que é a banalização do ser humano. $O$ propósito único e de realização da vida é ter, adquirir, acumular, isto é, o quantitativo e abstrato em detrimento do qualitativo e concreto. Além do mais, a relação entre presença e ausência que é próprio das representações também acomete os grupos sociais incluídos precariamente, principalmente os moradores de rua, pois seu corpo está presente nas ruas da cidade, mas sua essência, sua capacidade criativa, seu potencial como ator, seu direito, sua autonomia e dignidade estão ausentes, atribuindo-Ihes um aspecto de subhumanidade; presença e ausência percebida muitas vezes através do olhar, que ora enxerga, ora os torna invisíveis. Neste sentido, entendemos tais corpos como Harvey (2011), "um campo de batalha no interior e em torno do qual se acham em perpétua interação forças socioecológicas conflitantes de avaliação e representação".

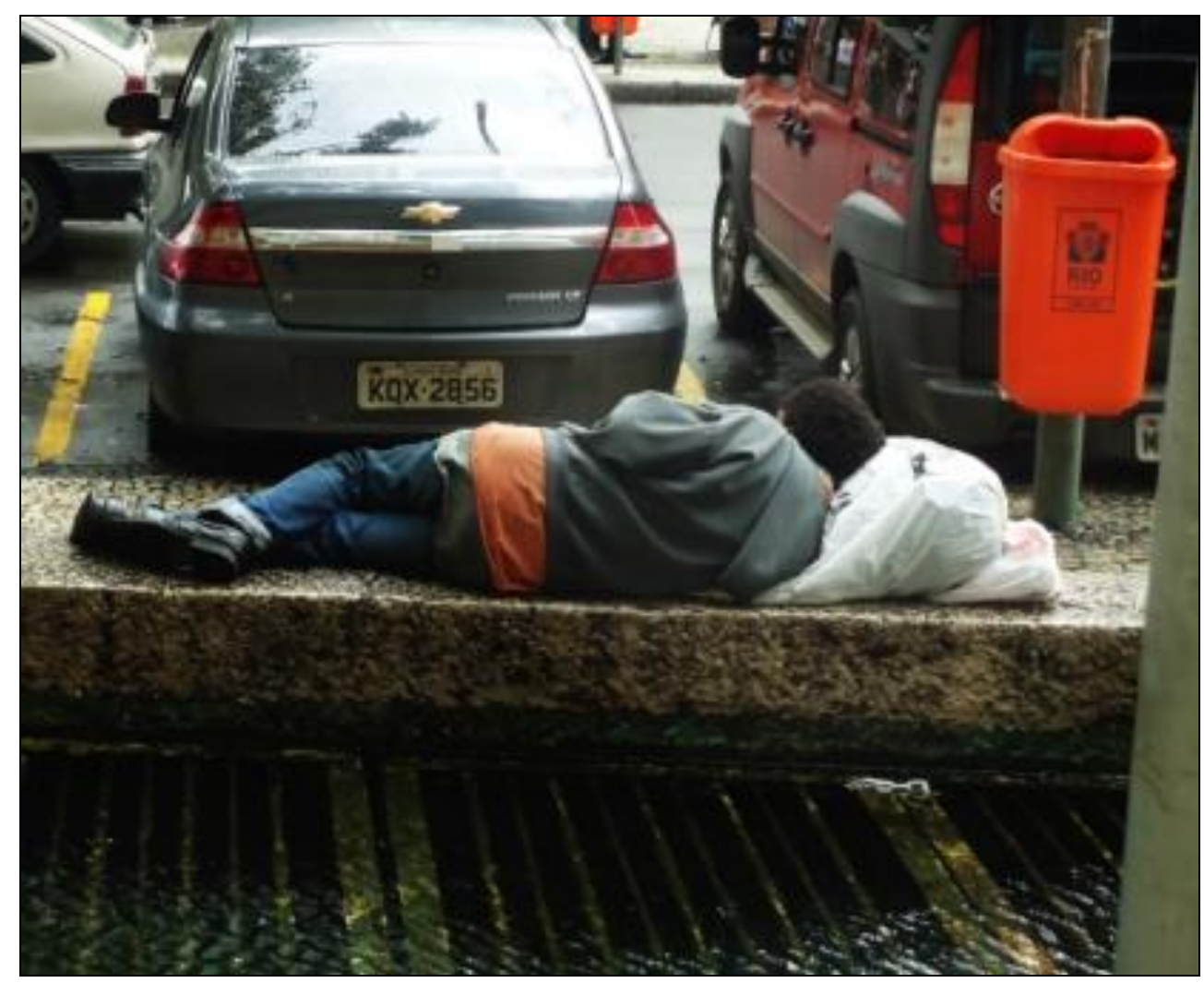

Figura 3 - Morador de rua do Centro da cidade. Morador de rua dormindo no Centro do Rio de Janeiro (arquivo pessoal). A cesta de lixo sugere algumas reflexões. Que tipo de amparo a prefeitura da cidade, ou a governança urbana oferece a estes indivíduos? Quais são os tipos 
de ação para solucionar o problema dos moradores de rua? Enquanto as agências multilaterais e os consultores pensam, dentro de seus escritórios, em estratégias empreendedoras para vender a cidade, talvez mais uma família perca sua moradia precária devido as remoções ou falta de condições para manter-se, tendo que procurar, na cidade que não permite os pobres habitar, algum abrigo. Curioso é que tão visível quanto a expressão dessa fotografia é a presença destes pobres nas ruas da cidade, porém, a banalização que obscurece a consciência política, o possível e as alternativas, também os torna invisíveis.

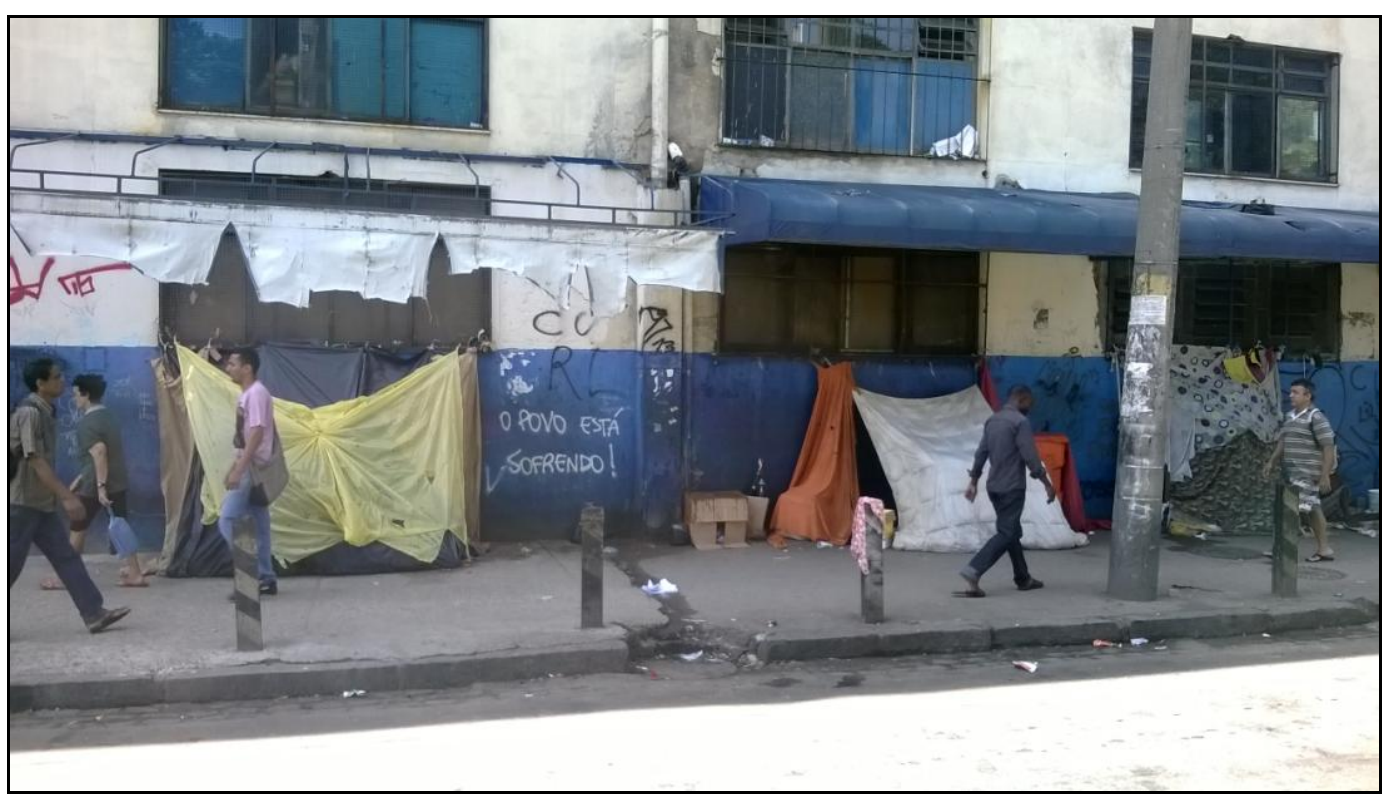

Figura 4 - Cabanas improvisadas (arquivo pessoal). As cabanas são o abrigo dos moradores de rua, instalados em frente ao prédio do Restaurante Popular Herbert de Souza (Betinho), na rua Senador Pompeu, 245-250, no Centro da cidade. Esses são exemplos de grupos incluídos precariamente em territorializações precárias. "O povo está sofrendo".

Observamos que os processos de mercadificação e militarização atuam na construção de uma cidade que comporta duas representações distintas, uma para a venda e o consumo, outra para o controle, a vigilância e a repressão. Tais representações são produto de uma concepção do espaço como mercadoria, portanto, que se presta à dominação, isto é, o valor de troca tem primazia em relação ao do valor de uso. Assim, os processos de mercadificação e militarização engendram representações da cidade que servem como recurso aos atores dominantes para legitimar suas intencionalidades, provocando, como estamos destacando, uma territorialização precária e formação de uma sub-humanidade - observada nas cenas de crack - destituída do direito à cidade.

Por outro lado, a banalização e opressão gera um quadro que se torna objeto de luta e contestação por parte de grupos, movimentos e mobilizações 
sociais, como é o caso da "Cristolândia", uma forma de luta empreendida por missionários que visa combater não somente as cracolândias, mas que pode se estender à sociedade inteira, uma vez que as cenas de crack são expressão da banalização do espaço - observada na miséria e na precariedade destes grupos - resultado da reprodução das relações sociais de produção. A partir de um espaço de representação, um espaço imaginado e concebido como "Cristolândia", atua no sentido de devolver aos grupos sub-humanizados das ruas a "sociabilidade dos humanos", não sem problemas. Entretanto, é o momento onde entendemos que, dentro do espaço conceitualizado como fechado, imutável e sem alternativas, encontramos rachaduras e possibilidades. Identificar representações que permitem trabalhar com 0 possível é uma tarefa urgente aos que lutam por uma revolução urbana que promova liberdade, justiça e direito à cidade. É preciso destituir as representações dominantes que sustentam a cidade como mercadoria e a vida para o consumo, restaurando a cidade como obra; imaginando e produzindo espaços onde a revolução da vida cotidiana possa se realizar; reapropriar-se do urbano como lugar de encontro e celebração da vida, não mais da como lócus da opressão.

\section{Referências}

FERREIRA, A. A cidade do século XXI: segregação e banalização do espaço. Rio de Janeiro. Editora Consequência, 2011.

FIOCRUZ. Livreto domiciliar e Livreto Epidmeológico. Disponível em: $<$ http://portal.fiocruz.br/pt-br/content/maior-pesquisa-sobre-crack-j\%C3\%A1feita-no-mundo-mostra-o-perfil-do-consumo-no-brasil> Acesso em: 13 de setembro de 2013.

FONTES, V. Capitalismo, exclusões e inclusão forçada IN Revista Tempo, Departamento de História UFF, vol.2, oㅡ, junho. Relume Dumaroa, Rio de Janeiro, 1997.

HAESBAERT, R. O mito da desterritorialização. Rio de Janeiro, Bertrand Brasil, 2004.

HARVEY, D. A Produção Capitalista do Espaço. São Paulo, Editora Annablume, 2005.

Loyola, 2011.

. Espaços de Esperança. São Paulo, 4ª edição. Edições 
Space as a key word. In HARVEY, David. Spaces of global capitalism. Towards a theory of uneven geographical development. New York: Verso, 2006.

LAGO, L. Desigualdades e segregação na metrópole: O Rio de Janeiro em tempo de crise. Rio de Janeiro. Editora Revan, 2000.

LEFEBVRE, H. 1986. Le retour de la dialetique: 12 mots clef pour le monde moderne. Paris, Messidor/Éditions Sociales.

. La presencia y la ausencia: contribuiciones a la teoria de las representaciones. Fondo de Cultura Economica, México, 1983.

. The Production of Space. Blackwell Publishing, 1991.

. Espaço e Política. Belo Horizonte, UFMG, 2008.

LUFTI, E.P.; SOCHACZEWSKI, S. \& JAHNEL, T. C. As representações e o possível. In: MARTNS, J. de S. (org.). Henry Lefebvre e o retorno da dialética. São Paulo: Hucitec, 1996. p. 87-97.

MARTINS, J. Exclusão social e a Nova desigualdade. Paulus, São Paulo, 1997.

PEET, R. Imaginários de Desenvolvimento. IN: Fernandes, B.M; Marques, M.I; Suzuki, J.C.(orgs). Geografia Agrária: Teoria e poder, São Paulo, Expressão Popular, 2007.

SANTOS, M. O espaço dividido: os dois circuitos da economia urbana dos países subdesenvolvidos. São Paulo: EDUSP, 2ª edição, 2004.

SOUZA, M. O desafio metropolitano: Um estudo sobre a problemática sócioespacial nas metrópoles brasileiras. Rio de janeiro, Bertrand Brasil, 2005. 